\title{
Jean-François Vallée, Le corbeau et la cymbale. Etienne Dolet et le Cymbalum mundi
}

\section{Filippo Fonio}

\section{(2) OpenEdition}

12 Journals

\section{Edizione digitale}

URL: http://journals.openedition.org/studifrancesi/30052

DOI: 10.4000/studifrancesi.30052

ISSN: 2421-5856

\section{Editore}

Rosenberg \& Sellier

\section{Edizione cartacea}

Data di pubblicazione: 1 avril 2006

Paginazione: 140

ISSN: 0039-2944

\section{Notizia bibliografica digitale}

Filippo Fonio, «Jean-François Vallée, Le corbeau et la cymbale. Etienne Dolet et le Cymbalum mundi», Studi Francesi [Online], 148 (XLX | I) | 2006, online dal 30 novembre 2015, consultato il 19 avril 2021. URL: http://journals.openedition.org/studifrancesi/30052 ; DOI: https://doi.org/10.4000/studifrancesi. 30052

Questo documento è stato generato automaticamente il 19 avril 2021.

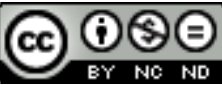

Studi Francesi è distribuita con Licenza Creative Commons Attribuzione - Non commerciale - Non opere derivate 4.0 Internazionale. 


\title{
Jean-François Vallée, Le corbeau et la cymbale. Etienne Dolet et le Cymbalum mundi
}

\author{
Filippo Fonio
}

\section{NOTIZIA}

JEAN-FRANÇOIS VALLÉE, Le corbeau et la cymbale. Etienne Dolet et le Cymbalum mundi, «Bibliothèque d'Humanisme et Renaissance», LXVII, 1 (2005), pp. 121-135.

1 L'ipotesi dello studioso è che il corbeau, il delatore del Cymbalum mundi, responsabile dell'interdizione dell'opera da parte del re, sia Etienne Dolet, con il quale Des Périers aveva in precedenza collaborato. Gli argomenti a sostegno sono anzitutto di natura intratestuale, in particolare inerenti il fatto che Dolet sarebbe il bersaglio di due episodi del Cymbalum, il secondo dialogo, dietro il quale vedere una parodia del Dialogus de imitatione Ciceroniana, adversus Desiderium Erasmum Roterodamum, pro Christophoro Longolio di Dolet (1535), e la figura di Hylactor nel quarto dialogo. Dalla possibile identificazione con il cane parlante e con la sua professione di ateismo, Dolet avrebbe avuto da temere (dati anche i già forti sospetti sulla sua irreligiosità che circolavano a corte), cosa che lo avrebbe spinto a una denuncia per scongiurare la diffusione del libro. Quasi in contemporanea con l'interdetto del re, per passare agli elementi contestuali, lo stesso François I aveva concesso a Dolet un insolito privilegio di edizione, a carattere di monopolio e di durata decennale, coperto da diritti molto estesi sulle opere da lui pubblicate. Se non si trattasse di una coincidenza, tale circostanza renderebbe assai probabile un'ingerenza di Dolet a corte in materia di editoria, tanto più giustificata in quanto si trattava di impedire la circolazione di uno scritto che poteva costituire una minaccia per le sue relazioni. 